developing nations like Vietnam carry a substantial portion of the burden. Our objective was to improve approaches for work-related injury surveillance in developing countries to identify or prioritise prevention opportunities.

Methods We administered a cross-sectional survey to 2615 households (99\% response) in a rural, rapidly developing community in Viet Nam. We collected information about selfreported work-related injuries and annual hours worked in each industry. Using descriptive and regression analyses we explored the role of various employment scenarios (eg, overlapping work, work schedules) and activities leading to injury. Results 1169 work-related injuries were reported during the year (Incidence Rate (IR) 203/1000 Full Time Equivalents (FTE)). We found male workers with multiple jobs had higher injury rates than those with only one job. A common situation of working in both agriculture and industry increased the injury risk substantially in both agriculture work (IR 484/1000 FTE) and in the primary industry job (IR 378/1000 FTE) compared to working individually in those industries (266 and $232 / 1000$ FTE respectively). We also assessed the impact of various activities and work schedules on the risk of injury.

Conclusions Work and home life, agricultural work and work in industry are extremely intertwined in Vietnam. We documented the impact of the intersection of agriculture work with industrial work on the risk of occupational injuries in this one community and suggest necessary changes in surveillance methodology in economies undergoing shifts in employment.

78 THE CHANGING STRUCTURE OF WORK AND

\title{
IMPLICATIONS FOR THE RISK OF WORK-RELATED INJURY IN DEVELOPING COUNTRIES: LESSONS LEARNED FROM XUAN TIEN, VIETNAM
}

Helen Marucci-Wellman, Joanna Willetts Liberty Mutual Research Institute for Safety, Hopkinton, USA

10.1136/oemed-2011-100382.78

Objectives Injuries are a leading cause of death and disability worldwide despite widespread under-reporting. Rapidly 